\title{
Association Between Digoxin Use and Cancer Incidence: A Propensity Score-Matched Cohort Study With Competing Risk Analysis
}

\author{
Chi-Jung Tai ${ }^{1,2}$, Yi-Hsin Yang ${ }^{3,4}$, Tzyy-Guey Tseng $^{5}$, Fang-Rong Chang ${ }^{1,6,7,8 *}$ and \\ Hui-Chun Wang ${ }^{1,6,7,8 *}$
}

${ }^{1}$ Graduate Institute of Natural Products, College of Pharmacy, Kaohsiung Medical University, Kaohsiung, Taiwan, ${ }^{2}$ Department of Family Medicine, Pingtung Hospital, Ministry of Health and Welfare, Pingtung, Taiwan, ${ }^{3}$ School of Pharmacy, College of Pharmacy, Kaohsiung Medical University, Kaohsiung, Taiwan, ${ }^{4}$ National Institute of Cancer Research, National Health Research Institutes, Tainan, Taiwan, ${ }^{5}$ Department of Family Medicine, Kaohsiung Medical University Hospital, Kaohsiung Medical University, Kaohsiung, Taiwan, ${ }^{6}$ Department of Marine Biotechnology and Resources, National Sun Yat-sen University, Kaohsiung, Taiwan, ${ }^{7}$ Drug Development and Value Creation Research Center, Kaohsiung Medical University, Kaohsiung, Taiwan, ${ }^{8}$ Department of Medical Research, Kaohsiung Medical University Hospital, Kaohsiung Medical University, Kaohsiung, Taiwan

OPEN ACCESS

Edited by: Robert Clarke,

University of Minnesota Twin Cities, United States

Reviewed by:

Hoi Huen Chan, Hong Kong Polytechnic University,

Hong Kong Xiaoxin Zhang,

Jiangsu University, China

*Correspondence:

Fang-Rong Chang aaronfrc@kmu.edu.tw

Hui-Chun Wang

wanghc@kmu.edu.tw

Specialty section: This article was submitted to Pharmacology of Anti-Cancer Drugs,

a section of the journal

Frontiers in Pharmacology

Received: 20 May 2020 Accepted: 22 February 2021

Published: 31 March 2021

Citation:

Tai C-J, Yang Y-H, Tseng T-G, Chang F-R and Wang H-C (2021) Association Between Digoxin Use and Cancer Incidence: A Propensity Score-

Matched Cohort Study With

Competing Risk Analysis.

Front. Pharmacol. 12:564097.

doi: 10.3389/fphar.2021.564097
Background: Previous studies neglected death as a critical competing risk while estimating the cancer risk for digoxin users. Therefore, the current study aims to assess the effectiveness of digoxin on cancer prevention by competing risk analysis.

Methods: We performed a population-based retrospective cohort study using the Taiwan National Health Insurance Research database between 1998 and 2010. After one-to-one propensity score-matching from 36,160 patients with defined criteria, we enrolled 758 patients both in digoxin and $\beta$-blocker group for further analysis.

Results: The results showed that the digoxin group had higher all-cause mortality than the $\beta$-blocker group in the 4-year (10.4 vs. 4.9\%) and 8 years (13.6 vs. $7.0 \%$ ) follow-up. The subdistribution HR of cancer incidence in the digoxin group compared to the $\beta$-blocker group was 1.99 (95\% confidence interval [Cl]: 1.22-3.01) and 1.46 (95\% Cl: 1.01-2.15) in the 4 years and 8 years follow-up, respectively.

Conclusions: The result of our study showed the usage of digoxin has no benefit in cancer prevention compared with $\beta$-blocker. The possibility of $\beta$-blocker as a new drug candidate for cancer prevention needs further clinical evaluation. The current study also emphasized the necessity of competing risk analysis applying to similar clinical researches.

Keywords: $\beta$-blocker, competing risk analysis, cancer, digoxin, propensity-score matching

\section{INTRODUCTION}

Although plants expressing cardiac glycosides have been used in medicine since ancient Egyptians times, digoxin, a potent inhibitor of $\mathrm{Na}^{+} / \mathrm{K}^{+}$-ATPase, was only first approved for the treatment of heart failure (HF) in 1998 by the United.States. Food and Drug Administration (Uretsky et al., 1993). Then, digoxin is currently used in patients with HF, atrial fibrillation (AF), and atrial flutter (AFL) (Sethi et al., 2018). However, since the development of novel drugs for HF, including $\beta$-blockers, angiotensin-converting-enzyme inhibitors (ACEIs), and angiotensin receptor blockers (ARBs), 
digoxin started to play a limited role in the treatment of patients with HF. Moreover, the prescriptions of digoxin have been declined gradually in patients with HF, AF or AFL because of its possible toxicity, narrow therapeutic range, and the potential for drug-drug interactions (Eichhorn and Gheorghiade, 2002; Xie et al., 2017; Sethi et al., 2018).

In addition to positive inotropic effects and the ability to decrease ventricular rates, repurposing digoxin as well as the development of other cardiac glycosides for cancer prevention and treatment has risen in highly discuss because of its anticancer properties in vitro (Prassas and Diamandis, 2008). There is no direct evidence of clinical trials to evaluate digoxin on cancer due to practical constraints. The available evidence predominantly based on observational studies but demonstrated controversial results. Digoxin was reported to increase the incidence rate of breast cancer using the database in Denmark, the United States, and the United Kingdom (Ahern et al., 2008; Biggar et al., 2013; Ahern et al., 2014; Couraud et al., 2014a). Moreover, digoxin use showed increased the risk of colorectal, lung, and uterine cancers analyzing the database in Denmark and the United Kingdom (Biggar et al., 2012; Boursi et al., 2014; Couraud et al., 2014b). On the contrary, studies from Sweden, Ireland, and Taiwan indicated that digoxin decreased the risk of prostate and liver cancers (Flahavan et al., 2014; Lim et al., 2015; Xie et al., 2017). The meta-analyses make a great effort to pool twenty-seven studies that showed digoxin increased the risk of estrogen receptor-positive breast cancer but not others (Osman et al., 2017); however, the heterogeneity of the previous studies might limit the data interpretation.

Probing deep into previous studies, we noticed several possible confounding factors that potentially contribute to the cancer risk associated with digoxin as follows. Firstly, some studies had confounding by indication, a phrase that refers to a situation where patient characteristics, rather than the intervention, are independent predictors of outcome (Cnossen et al., 2018). As a consequence, patients exposed and not exposed to digoxin might not be comparable, which hindered the relational inference (Biggar et al., 2012; Chung et al., 2017). Moreover, the previous studies neglected the possible cancer-preventive effect of concomitant medications, such as aspirin, ACEI, and ARB (Chung et al., 2017). Secondly, digoxin users are patients with HF, $\mathrm{AF}$, or AFL, whose all-cause mortality is high and most of the previous studies neglected the competing risk of death. The bias associated with the competing risk of death happened in study design and methods for statistical analysis. For example, a casecontrol study design using specific cancer database was not appropriate because death might occur before cancer diagnoses (Ahern et al., 2008). Additionally, conventional approaches to describe the risk of cancer, including KaplanMeier (KM) survival analysis and Cox proportional hazards regression, can overestimate the risk of cancer by ignoring the competing risk of death (Haggstrom et al., 2016). These methods may lead to a biased result, especially when there is a big difference in mortality between the two groups (Ahern et al., 2014; Xie et al., 2017). Thirdly, medication adherence is a crucial factor associated with the incidence of cancer (Forbes et al., 2018). Specific medication has an impact on cancer incidence only when it was prescribed for chronic conditions, which need to be taken on a long-term basis. However, the medication adherence was not described in detail (Karasneh et al., 2015), or the exposure of digoxin was low in the previous studies (Boursi et al., 2014).

The following approaches in this study try to minimize the possible confounders and avoid violation of the assumption. Firstly, we evaluated the cancer incidence between digoxin and $\beta$-blockers in patients with HF, AF, or AFL. The indication of digoxin and $\beta$-blockers was almost identical in selected clinical conditions, which prevented confounding by indication (Kirchhof et al., 2016). Secondly, we designed a retrospective cohort study propensity score-matched with age, sex, medical comorbidities, and concomitant medications using a populationbased National Health Insurance Research Database (NHIRD) in Taiwan. Finally, we calculated and matched the first-year cumulative defined daily dose (cDDD) of digoxin and $\beta$-blockers between two groups (Lin et al., 2016). The current study aimed to analyze the association between digoxin and cancer incidence through rigorous study design.

\section{METHODS}

\section{Data Source}

The current study used one of the subsets of NHIRD, which contained two million patients (approximately 10\% of Taiwan's population) randomly selected from NHI beneficiaries in Taiwan. Because the prescriptions of digoxin have been declining steadily over the last 15 years, which may have caused selection bias (Goldberger and Alexander, 2014), we used a dataset from 1997 to 2010 to reduce the possible selection bias due to clinical tendency.

\section{Study Cohort and Design}

We searched the records in NHIRD from 1998-2010 to identify patients aged $\geq 20$ years with newly diagnosed HF, AF or AFL in our study. HF, AF, or AFL patients were identified by the International Classification of Diseases Revision, Ninth Revision, Clinical Modification (ICD-9-CM) codes, where 428 is for HF, 427.31 code is for AF, and 427.32 code is for AFL. To enhance diagnostic validity, patients with at least three consistent diagnoses of $\mathrm{HF}$, AF, or AFL from outpatient medical records were enrolled in our study (Figure 1). We targeted $\beta$-blocker users as the control group because the clinical indication of digoxin and $\beta$-blockers was similar in patients with $\mathrm{HF}$, AF or AFL (Kirchhof et al., 2016; Ponikowski et al., 2016). The prescriptions of digoxin and $\beta$-blockers were selected by Anatomical Therapeutic Chemical (ATC) classification system and the corresponding drug codes from outpatient medical claims using NHIRD. For at least a 1 year baseline prescription period, a year from the first prescription of target medications was assigned as the index date (Figure 2). To quantify individual's exposure to target medications and medical adherence, the cDDD of target medications from the first prescription date to the index date (cDDD-1 year) were calculated (Tsai et al., 2016). 
Taiwan NHIRD cohort (1997-2010) 2 million enrollees: $\geqq 20$ years old with $\geqq 3$ times outpatient diagnosis of atrial fibrillation (AF) (ICD-9CM: 427.31) or atrial flutter (AFL) (427.32) or heart failure (428)

$$
(n=36,160)
$$

\begin{tabular}{|c|c|}
\hline & $\begin{array}{l}\text { Exclusion, } \boldsymbol{n}= \\
\text { 1. No use of } \beta \text {-blocker or digoxin }(n=16,998) \\
\text { 2. Patients who took combination of } \beta \text {-blocker and digoxin } \\
\text { or switch from one drug to the other }(n=7,010) \\
\text { 3. Prescription duration of } \beta \text {-blocker or digoxin }<1 \text { year, or } \\
\text { prescription interval }>180 \text { days }(n=8,557) \\
\text { 4. Cancer diagnosis prior to index date }(n=282)\end{array}$ \\
\hline \multirow[t]{2}{*}{$\begin{array}{l}\text { Digoxin group } \\
\quad(\boldsymbol{n}=\mathbf{1 , 1 0 4 )}\end{array}$} & $\begin{array}{l}\beta \text {-blocker group } \\
\quad(\boldsymbol{n}=\mathbf{2 , 2 7 1 )}\end{array}$ \\
\hline & $\begin{array}{l}\text { 1:1 Complete matching by sex and primary diagnosis, and } \\
\text { propensity score-matching by age, medication history, } \\
\text { medical comorbidities, and cumulative defined daily dose } \\
\text { (cDDD)-1 year }\end{array}$ \\
\hline $\begin{array}{l}\text { Digoxin group } \\
\quad(n=758)\end{array}$ & $\begin{array}{l}\beta \text {-blocker group } \\
\quad(n=758)\end{array}$ \\
\hline
\end{tabular}

FIGURE 1 | Study flow chart. Nhird, national health insurance research database.

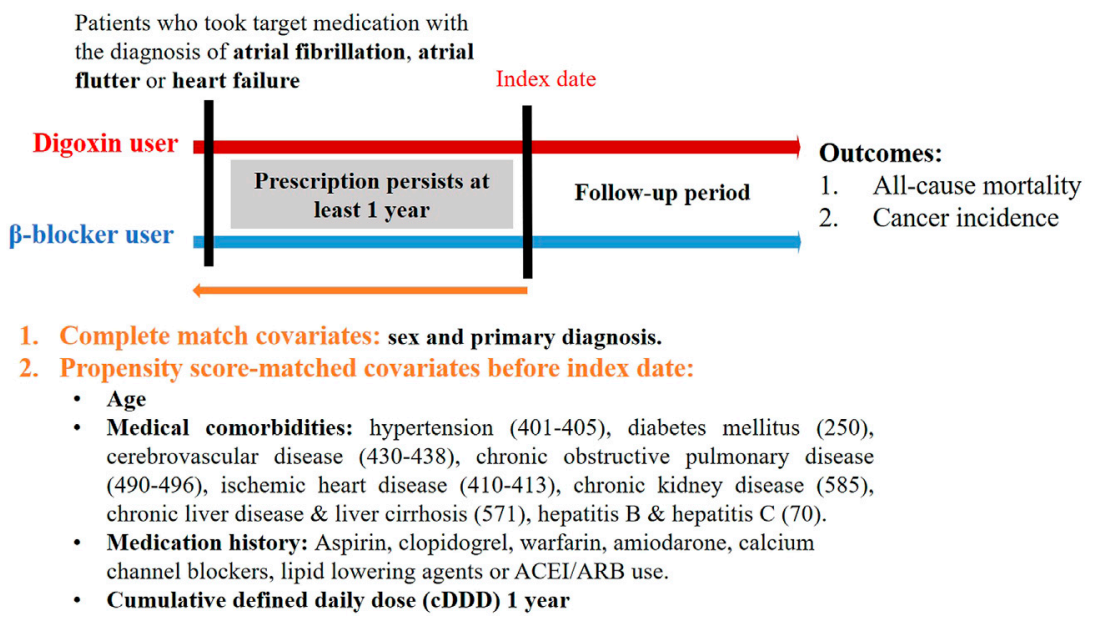

FIGURE 2 | Study design.

To enhance the validity of the current study, we made some exclusion criteria as follows (Figure 1): Firstly, patients without the use of digoxin and $\beta$-blockers in the treatment of HF, AF or AFL were excluded. Secondly, we excluded patients who have ever taken the combination of $\beta$-blockers and digoxin or switched from one drug to the other during the follow-up. Thirdly, drugs usually require long-term and sustained use to affect the incidence of cancer, so we excluded patients whose prescription duration of $\beta$-blockers and digoxin less than one year or prescription interval $>180$ days (Lam and Fresco, 2015). The process ensured medical adherence and persistence (Raebel et al., 2013). Finally, we excluded patients with cancer history prior to the index date (Figures 1,2).
To reduce demographic differences between the digoxin group and the $\beta$-blocker group, we performed propensity-score matching by age, sex, medical comorbidities, medication history and the CDDD of target medications (Lin et al., 2016). The medical comorbidities including hypertension, diabetes mellitus, cerebrovascular disease, chronic obstructive pulmonary disease, ischemic heart disease, chronic kidney disease, chronic liver disease or liver cirrhosis, and hepatitis $\mathrm{B}$ or $\mathrm{C}$ were selected by corresponding ICD-9-CM codes in outpatient medical claims previous to the index date (Figure 2). Medications such as aspirin, clopidogrel, warfarin, amiodarone, calcium channel blockers (CCBs), lipid-lowering agents, ACEI, and ARB were also selected as matching covariates, which were commonly prescribed to patients with $\mathrm{HF}, \mathrm{AF}$ or 
TABLE 1 | Clinical demographics of patients before and after 1:1 propensity score-matching.

\begin{tabular}{|c|c|c|c|c|c|c|}
\hline & \multicolumn{2}{|c|}{ Before matching } & \multirow[t]{2}{*}{$p$ Value } & \multicolumn{2}{|c|}{ 1: 1 matching } & \multirow[t]{2}{*}{ Standardized mean difference ${ }^{a}$} \\
\hline & $\begin{array}{l}\text { Digoxin } \\
\text { group } n=1104\end{array}$ & $\begin{array}{l}\beta \text {-blocker } \\
\text { group } n=2271\end{array}$ & & $\begin{array}{l}\text { Digoxin } \\
\text { group } n=758\end{array}$ & $\begin{array}{l}\beta \text {-blocker } \\
\text { group } n=758\end{array}$ & \\
\hline Age (years) & $71.8 \pm 13.7$ & $66.6 \pm 13.4$ & $<0.001^{\mathrm{b}}$ & $70.5 \pm 14.4$ & $70.2 \pm 12.2$ & 0.022 \\
\hline Male & 610 (55.3\%) & 1212 (53.4\%) & 0.30 & 412 (54.4\%) & 412 (54.4\%) & $<0.001$ \\
\hline \multicolumn{7}{|l|}{ Medication history } \\
\hline Aspirin & $526(47.6 \%)$ & 1295 (57.0\%) & $<0.001^{\mathrm{c}}$ & 394 (52.0\%) & 378 (49.9\%) & 0.042 \\
\hline Clopidogrel & $43(3.9 \%)$ & $303(13.3 \%)$ & $<0.001^{\mathrm{c}}$ & $41(5.4 \%)$ & $48(6.3 \%)$ & 0.038 \\
\hline Warfarin & $185(16.8 \%)$ & $146(6.4 \%)$ & $<0.001^{\mathrm{c}}$ & 95 (12.5\%) & $91(12.0 \%)$ & 0.015 \\
\hline Amiodarone & $74(6.7 \%)$ & $223(9.8 \%)$ & $0.003^{\mathrm{C}}$ & $59(7.8 \%)$ & $64(8.4 \%)$ & 0.022 \\
\hline CCBs & 430 (39.0\%) & 1293 (56.9\%) & $<0.001^{\mathrm{c}}$ & 350 (46.2\%) & $361(47.6 \%)$ & 0.028 \\
\hline Lipid lowering agents & $125(11.3 \%)$ & $672(29.6 \%)$ & $<0.001^{\mathrm{c}}$ & $111(14.6 \%)$ & $123(16.2 \%)$ & 0.044 \\
\hline ACEI/ARB & $656(59.4 \%)$ & 1472 (64.8\%) & $0.002^{c}$ & 467 (61.6\%) & $461(60.8 \%)$ & 0.016 \\
\hline \multicolumn{7}{|l|}{ Medical comorbidities } \\
\hline Hypertension & $663(60.1 \%)$ & $1853(81.6 \%)$ & $<0.001^{\mathrm{c}}$ & $554(73.1 \%)$ & $550(72.6 \%)$ & 0.011 \\
\hline Diabetes mellitus & $257(23.2 \%)$ & $624(27.5 \%)$ & $0.01^{c}$ & $197(26.0 \%)$ & $184(24.3 \%)$ & 0.039 \\
\hline Cerebrovascular disease & 249 (22.6\%) & 447 (19.7\%) & 0.05 & $173(22.8 \%)$ & $162(21.4 \%)$ & 0.034 \\
\hline COPD & 483 (43.8\%) & $651(28.7 \%)$ & $<0.001^{\mathrm{c}}$ & 291 (38.4\%) & 302 (39.8\%) & 0.029 \\
\hline Ischemic heart disease & $182(16.5 \%)$ & $663(29.2 \%)$ & $<0.001^{\mathrm{c}}$ & $159(21.0 \%)$ & $150(19.8 \%)$ & 0.030 \\
\hline Chronic kidney disease & 43 (3.9\%) & $148(6.5 \%)$ & $0.002^{c}$ & $36(4.8 \%)$ & $38(5.0 \%)$ & 0.009 \\
\hline Chronic liver disease & 117 (10.6\%) & 391 (17.2\%) & $<0.001^{\mathrm{c}}$ & $92(12.1 \%)$ & $96(12.7 \%)$ & 0.018 \\
\hline Chronic hepatitis B or C & $150(13.6 \%)$ & 467 (20.6\%) & $<0.001^{c}$ & $121(16.0 \%)$ & $124(16.4 \%)$ & 0.011 \\
\hline cDDD-1 year & $183.2 \pm 87.6$ & $155.7 \pm 122.2$ & $<0.001^{b}$ & $173.8 \pm 82.8$ & $177.4 \pm 142.1$ & 0.031 \\
\hline
\end{tabular}

$A C E I$ = angiotensin-converting enzyme inhibitor; $A R B=$ angiotensin receptor blockers; $C C B s=$ calcium channel blockers; $C O P D=$ chronic obstructive pulmonary disease; $c D D D=$ cumulative defined daily doseLipid lowering agents include statin, fibrates, ezetimibe and niacin.

${ }^{a}$ Standardized mean difference of more than 0.1 denotes meaningful imbalance in the baseline covariates.

${ }^{b}$ Independent t-test: $\mathrm{p}$-value $<0.05$.

${ }^{c}$ Chi-square test: $p$-value $<0.05$.

AFL. Additionally, we matched the cDDD-1 year between the digoxin group and the $\beta$-blocker group, which represented that medication adherence and dose-response effect were similar in two groups (Raebel et al., 2013). The cDDD-1 year represented the cumulative dose of target medications during the first year.

The primary outcome of the current study was cancer incidence (ICD-9-CM: 140-208), which was identified from the inpatient medical records. As we mentioned above, death was a competing risk event because its occurrence cannot be treated as independent censoring when analyzing the time to cancer occurrence. Therefore, the in-hospital mortality was identified as a competing risk event from the inpatient medical records using NHIRD. The current study was approved by the Institutional Review Board of Antai Medical Care Cooperation Antai-Tian-Sheng Memorial Hospital in 2018.

\section{Statistical Analyses}

Descriptive statistics were used to assess patients' demographics. The standardized mean differences were calculated for the matched cohort to assess balance in measured baseline covariates (Austin, 2009). Some researchers had proposed that a standardized difference of more than 0.1 denoted meaningful imbalance in the baseline covariates (Normand et al., 2001). The adjusted HR of all-cause mortality and cancer incidence were calculated by Cox proportional hazard model adjusting for possible confounders. Importantly, the cumulative cancer incidence was estimated by the cumulative incidence competing risk method, which incorporated competing risks of death in the cumulative incidence function (Hsieh et al., 2015). The subdistribution HR of cancer incidence was performed by the proportional subdistribution hazards regression. All of the analyses were conducted using SAS version 9.4 (SAS Institute Inc., Cary, NC, United States), and SAS macros \%CIF and \%PSHREG were used for competing risk analyses (Lin and Johnston, 2012; Kohl et al., 2015).

\section{RESULTS}

\section{Baseline Characteristics}

As shown in Figure 1, there were 36,160 newly diagnosed patients with HF, AF or AFL who met inclusion criteria. Following the application of exclusion criteria, we identified 1,104 patients in the digoxin group and 2,271 patients in the $\beta$-blocker group. Prior to propensity score matching, digoxin group patients were significantly older $(71.8 \pm 13.7$ vs. $66.6 \pm 13.4$ years $)$, and had a higher rate of warfarin usage (16.8 vs. $6.4 \%)$ and chronic obstructive pulmonary disease (COPD) (43.8 vs. 28.7\%) compared to the $\beta$-blocker group (Table 1). Moreover, the cDDD-1 year was higher in the digoxin group than in the $\beta$-blocker group $(183.2 \pm 87.6$ vs. $155.7 \pm 122.2)$. In contrast, the $\beta$-blocker group more frequently used aspirin, clopidogrel, amiodarone, CCBs, lipid-lowering agents, and ACEI/ARB concomitantly. They also had higher prevalence of hypertension, diabetes mellitus, cerebrovascular disease (CVD), ischemic heart disease, chronic kidney disease (CKD), chronic liver disease, and hepatitis B or C (Table 1). These data suggested 
TABLE 2 | All-cause Mortality and Cancer incidence Between Two Groups After 1:1 propensity score-matching.

\begin{tabular}{|c|c|c|c|c|c|c|}
\hline & $\begin{array}{c}\text { Digoxin group } \\
\quad n=758\end{array}$ & $\begin{array}{c}\beta \text {-blocker group } \\
\quad n=758\end{array}$ & $\begin{array}{c}\text { Adjusted hazard } \\
\text { ratio } \\
(95 \% \mathrm{Cl})\end{array}$ & $p$ value & $\begin{array}{c}\text { Subdistribution hazard } \\
\text { ratio } \\
(95 \% \mathrm{Cl})\end{array}$ & $p$ value \\
\hline \multicolumn{7}{|l|}{ 4-year follow-up } \\
\hline All-cause mortality & 79 (10.4\%) & 37 (4.9\%) & $1.74(1.18-2.59)$ & $0.006^{a}$ & NA & NA \\
\hline Cancer incidence & $43(5.7 \%)$ & 30 (4.0\%) & $1.26(0.79-2.02)$ & 0.34 & $1.99(1.22-3.01)$ & $0.006^{a}$ \\
\hline \multicolumn{7}{|l|}{ 8-year follow-up } \\
\hline All-cause mortality & 103 (13.6\%) & 53 (7.0\%) & $1.41(1.01-1.97)$ & $0.046^{a}$ & NA & NA \\
\hline Cancer incidence & $57(7.5 \%)$ & $40(5.3 \%)$ & $1.17(0.78-1.76)$ & 0.45 & $1.46(1.01-2.15)$ & 0.054 \\
\hline
\end{tabular}

$\mathrm{CCB}=$ calcium channel blocker; $\mathrm{Cl}=$ confidence interval; Cox proportional hazards regression.

${ }_{\mathrm{a}}^{\mathrm{p}}$ value $<0.05$ Subdistribution hazards regression.

${ }^{b} \mathrm{p}$ value $<0.05$

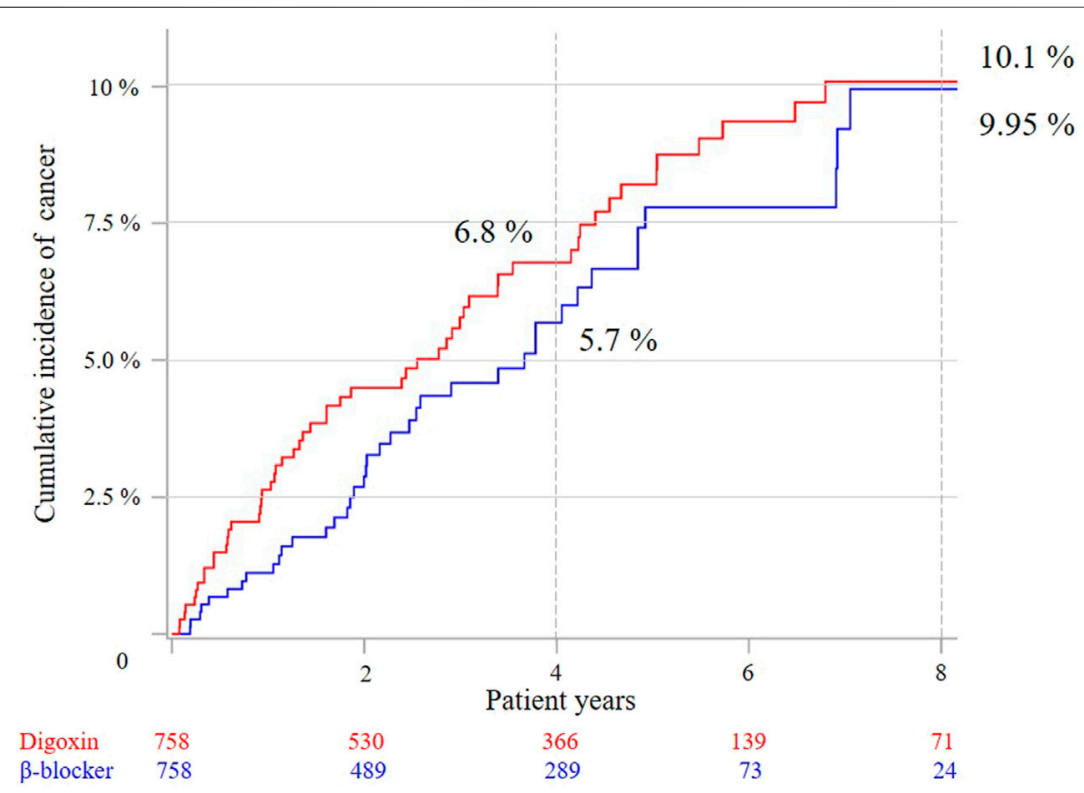

FIGURE 3 | Cumulative cancer incidence between the two groups after 1:1 propensity-score matching by competing risk analysis.

that the clinical demographics of patients taking digoxin and $\beta$-blocker were still quite different.

After 1:1 propensity-score matching by criteria, there were 758 patients in the digoxin group and 758 patients in the $\beta$-blocker group. The cancer-related covariates were well-balanced after matching (Table 1). The mean follow-up was $4.3 \pm 3.1$ years. The mean age of two groups was $70.5 \pm 14.4$ vs. $70.2 \pm 12.2$ years in the digoxin and the $\beta$-blocker group, respectively. There were more male patients ( 54.4 vs. $45.6 \%$ ) in both groups. More than $50 \%$ of patients concurrently took aspirin or ACEI/ARB with target medications, and more than $70 \%$ of patients had a history of hypertension.

\section{Outcomes}

After 1:1 propensity-score matching by covariates, the all-cause mortality was statistically higher for the digoxin group (10.4 vs. $4.9 \%$ ) in the 4 years follow-up and 8 years follow-up (13.6 vs. $7.0 \%$ ) (Table 2). Competing risk analyses indicated that the digoxin group had higher cancer cumulative incidence than the $\beta$-blocker group (Figure 3). Moreover, subdistribution HR (SHR) calculated by proportional subdistribution hazard regression was 1.99 for the digoxin group (95\% CI: $1.22-3.01$ ) in the 4-years follow-up, and 1.46 (95\% CI: 1.22-3.01) in the 8 years follow-up (Table 2). The adjusted HR (adjHR) estimated by traditional Cox proportional regression model showed no statistical difference between the two groups.

\section{DISCUSSION}

Given that natural cardiac glycosides showed an anti-cancer property in a verity of cancer cells, but also because the discovering $\mathrm{Na}^{+} / \mathrm{K}^{+}$-ATPase can function as a signal transducer, the opportunity of repurposing digoxin as well as the development of other cardiac glycosides as anti-cancer drugs have increased interest in previous studies (Prassas and 
Diamandis, 2008). Digoxin exhibits anticancer property through inducing apoptotic and immunogenic cell death (Menger et al., 2012; Kulkarni et al., 2016). It also disturbed HIF-1, FAK, and NFkB pathways, which potential underlie its anti-angiogenic effect (Trenti et al., 2017; Wang et al., 2017; Ouyang et al., 2018). In contrast, the previous study suggested that an estrogen-like effect of digoxin might increase the incidence of breast cancer who receive hormone therapy (Biggar, 2012). Therefore, the anti-cancer properties of digoxin were inconclusive and different in specific cancer types. Besides, the narrow therapeutic window of digoxin leads to a consideration of drug impact on normal cells, which has not been evaluated in previous in vitro studies (Botelho et al., 2019). Concerning effectiveness and safety, the results of clinical observations appear to be of higher priority than preclinical studies.

To evaluate the association of digoxin and cancer incidence in clinical condition, we conducted a population-based, propensity score-matched, retrospective cohort study with competing risk analysis, which was not applied to previous observational studies. Moreover, we put concomitant medications into propensityscore matching covariates, which minimized the confounding by indication because the concordance between patients' clinical condition with medication use was higher than concordance with clinical diagnosis (Wu et al., 2014). Our result showed that digoxin group had significantly higher cancer incidence and risk than the $\beta$-blocker group.

\section{Conventional Survival Analysis vs. Competing Risk Analysis}

KM survival analysis and Cox proportional hazards regression are often adapted for assessing the time to an event such as death or drop-out from the cohort study (Hsieh et al., 2015). When these methods are used to describe outcomes other than all-cause mortality in patients with a significant risk of death, the result may be biased (Berry et al., 2010). The cancer incidence and adjHR calculated by Cox regression model showed no significant difference between the digoxin group and the $\beta$-blocker group. However, allcause mortality was significantly different between the two groups in the current study. The subdistribution hazards regression demonstrated that death events might be treated as censored events, and the risk might be underestimated in the conventional Cox proportional regression (Lau et al., 2009). Therefore, the current study proposed that competing risk analysis should be commonly applied for similar clinical observation studies.

\section{Cancer Risk of Digoxin Use Was Influenced by Concomitant Medications}

Digoxin users often took concomitant medications, such as aspirin, ACEI, and ARB because of complicated clinical conditions. However, these medications might influence cancer incidence. For example, clinical recommendations for aspirin-based chemoprevention strategies have recently been established for the prevention of cancer (Drew et al., 2016). However, the efficacy of clopidogrel or warfarin as an anticancer agent was inconclusive (Haaland et al., 2017; Bruno et al., 2018). Moreover, although recent meta-analysis studies showed neutral effects of ACEI/ARB on cancer incidence (Bangalore et al., 2011; Zhao et al., 2016), the association between cancer risk and ACEI/ARB still had conflicting conclusions. In contrast, amiodarone may be associated with an increased risk of incident cancer, especially in men (Su et al., 2013). Therefore, possible concomitant medications might interfere with the interpretation of the previous studies (Chung et al., 2017; Xie et al., 2017). The current study used propensity-score matching to minimize the effect of concomitant medications.

\section{The Association of Cancer Risk and Digoxin and Hormone Receptors}

Ahern and colleagues observed an increased risk of breast cancer in Danish patients treated with digoxin (OR:1.30; 95\% CI: 1.14-1.48) (Ahern et al., 2008). However, 32-37\% of patients received hormone replacement therapy in that study and the study did not include subgroup analysis of breast cancer incidence in patients without hormone replacement therapy. The result might be interfered with the effect of hormone replacement therapy on the incidence of breast cancer. Ahern and colleagues also studied the Unites States registered nurses database, where the results indicated higher HR in digoxin users in the estrogen receptor (ER)-positive breast cancer $(\mathrm{HR}=1.45 ; 95 \% \mathrm{CI}: 1.13-1.86)$ compared to the ER-negative breast cancer $(\mathrm{HR}=1.21 ; 95 \% \mathrm{CI}$ : 0.52-2.37) (Ahern et al., 2014). However, data on digoxin exposure in that study was collected by questionnaires biennially, which might not reflect the true medical adherence and dose-response effects. In our opinion, physicians should pay more attention to the concomitant use of digoxin and hormone therapy.

Although cardiac glycosides decrease expression of prostatespecific antigen by down-regulation of prostate-derived Ets factor (Juang et al., 2010), digoxin treatment did not show conclusive anti-cancer effects on prostate cancer in previous conducted studies. Platz and colleagues suggested that regular digoxin users for $\geq 10$ years had a lower prostate cancer relative risk of 0.54 (95\% CI $0.37-0.79$, p-trend <0.001) compared to nonusers (Platz et al., 2011). In contrast, Kaapu and colleagues showed no significant association was between digoxin use and overall prostate cancer risk $(\mathrm{OR}=0.95 ; 95 \% \mathrm{CI}: 0.89-1.01)$ or advanced prostate cancer risk $(\mathrm{OR}=0.90 ; 95 \% \mathrm{CI}: 0.77-1.05)$ (Kaapu et al., 2015). The report concluded that sotalol, but not digoxin was associated with decreased prostate cancer risk.

\section{Limitations}

Although the study generated significant findings, our results should be interpreted with caution. Firstly, the results are limited to patients with HF, AF or AFL. The effect of digoxin on healthy participants could not be obtained in the NHIRD study. Secondly, although we used multiple strategies to minimize confounding by propensity-score matching, the current observational study might have residual confounding factors and cannot prove causality. Third, the medical adherence and some time-varying changes might influence the result. Therefore, the result was less evident in 8 years than 4 years follow up. Finally, the incidence of specific cancer types was not evaluated because the cancer case numbers were too low for advance analysis. 


\section{Insights for Further Translational Study and Clinical Trials}

Although digoxin proves its anti-cancer effects in vitro, for now, it is virtually impossible to perform a clinical trial to evaluate the association of digoxin and cancer incidence for the healthy population because of the safety issues of digoxin. We suggest that researchers can screen natural cardiac glycosides with the same or better anti-cancer effects but lower cardio-inotropic effects compared with digoxin.

According to previous studies, the possible anti-cancer mechanisms of $\beta$-blockers were as follows. The mode of action of $\beta$-blockers in vitro linked to cancer growth inhibition through impaired production of vascular endothelial growth factor (VEGF) (Watkins et al., 2015), decreased cytokine serum levels (Haldar et al., 2018), and enhanced the effect of epidermal growth factor receptor (EGFR) inhibitors (Nilsson et al., 2017). One observational study indicated that patients taking propranolol had an $80 \%$ risk reduction in melanoma recurrence (De Giorgi et al., 2018), while another study suggested that the use of $\beta$-blockers might be associated with more prolonged survival in patients with stage IV colorectal cancer (Jansen et al., 2014). However, anti-cancer effect dose not equal to the prevention of cancer. There is still a knowledge gap between anti-cancer effect derived from basic study and clinical evidence of cancer prevention. Further basic study and clinical trial are needed to fill the gap.

\section{CONCLUSION}

Our study is the first to include the death event as the competing risk while evaluating the association of digoxin and cancer incidence. Our results suggest traditional Cox regression model underestimated the risk. After considering the risk of death, digoxin users had a higher risk of cancer incidence compared to $\beta$-blockers. The current study demonstrated the necessity of competing risk analysis applying to similar clinical researches.

For clinical use for cancer prevention, the assessment of digoxin or other natural derived cardiac glycosides should consider their safety issue first. Further studies are required to evaluate their effectiveness.

\section{REFERENCES}

Ahern, T. P., Lash, T. L., Sørensen, H. T., and Pedersen, L. (2008). Digoxin treatment is associated with an increased incidence of breast cancer: a population-based casecontrol study. Breast Cancer Res. 10, R102. doi:10.1186/bcr2205

Ahern, T. P., Tamimi, R. M., Rosner, B. A., and Hankinson, S. E. (2014). Digoxin use and risk of invasive breast cancer: evidence from the Nurses' Health Study and meta-analysis. Breast Cancer Res. Treat. 144, 427-435. doi:10.1007/s10549014-2886-x

Austin, P. C. (2009). Balance diagnostics for comparing the distribution of baseline covariates between treatment groups in propensity-score matched samples. Statist. Med. 28, 3083-3107. doi:10.1002/sim.3697

\section{DATA AVAILABILITY STATEMENT}

The data analyzed in this study is subject to the following licenses/ restrictions: The use of dataset needs the permission of the Ministry of Health and Welfare, Taiwan. Requests to access these datasets should be directed to Ministry of Health and Welfare, Taiwan.

\section{ETHICS STATEMENT}

The studies involving human participants were reviewed and approved by the Institutional Review Board of Antai Medical Care Cooperation Antai-Tian-Sheng Memorial Hospital. Written informed consent for participation was not required for this study in accordance with the national legislation and the institutional requirements.

\section{AUTHOR CONTRIBUTIONS}

CT, FC, and HW designed the research. CT and YY performed the analysis. CT. and TT wrote the manuscript. YY, FC, and HW made the critical revision of the manuscript.

\section{FUNDING}

This study was supported by the grants from the Ministry of Science and Technology, Taiwan (MOST 108-2320-B-037-022MY3, 108-2811-B-037-511, 109-2927-I-037-502, awarded to FC, and MOST107-2320-B-037-008-MY3, awarded to HW). Also, this research was also funded by the Drug Development and Value Creation Research Center, Kaohsiung Medical University and Department of Medical Research, Kaohsiung Medical University Hospital, awarded to FC. (grant number: KMU-TC108A03-11). This research was also supported by National Sun Yat-Sen University-Kaohsiung Medical University Joint Research Project (NSYSUKMU109-I005-3) awarded to HW.

\section{ACKNOWLEDGMENTS}

We thank the statistical support of colleagues from the Center for Medical Informatics and Statistics, Kaohsiung Medical University.

Bangalore, S., Kumar, S., Kjeldsen, S. E., Makani, H., Grossman, E., Wetterslev, J., et al. (2011). Antihypertensive drugs and risk of cancer: network meta-analyses and trial sequential analyses of 324168 participants from randomised trials. Lancet Oncol. 12, 65-82. doi:10.1016/s1470-2045(10)70260-6

Berry, S. D., Ngo, L., Samelson, E. J., and Kiel, D. P. (2010). Competing risk of death: an important consideration in studies of older adults. J. Am. Geriatr. Soc. 58, 783-787. doi:10.1111/j.1532-5415.2010.02767.x

Biggar, R. J., Andersen, E. W., Kroman, N., Wohlfahrt, J., and Melbye, M. (2013). Breast cancer in women using digoxin: tumor characteristics and relapse risk. Breast Cancer Res. 15, R13. doi:10.1186/bcr3386

Biggar, R. J. (2012). Molecular pathways: digoxin use and estrogen-sensitive cancers-risks and possible therapeutic implications: figure 1. Clin. Cancer Res. 18, 2133-2137. doi:10.1158/1078-0432.ccr-11-1389 
Biggar, R. J., Wohlfahrt, J., and Melbye, M. (2012). Digoxin use and the risk of cancers of the corpus uteri, ovary and cervix. Int. J. Cancer 131, 716-721. doi:10. $1002 /$ ijc. 26424

Botelho, A. F. M., Pierezan, F., Soto-Blanco, B., and Melo, M. M. (2019). A review of cardiac glycosides: structure, toxicokinetics, clinical signs, diagnosis and antineoplastic potential. Toxicon 158, 63-68. doi:10.1016/j.toxicon.2018.11.429

Boursi, B., Haynes, K., Mamtani, R., and Yang, Y.-X. (2014). Digoxin use and the risk for colorectal cancer. Pharmacoepidemiol Drug Saf. 23, 1147-1153. doi:10. 1002/pds.3717

Bruno, A., Dovizio, M., Tacconelli, S., Contursi, A., Ballerini, P., and Patrignani, P. (2018). Antithrombotic agents and cancer. Cancers (Basel) 10 (8), 253. doi:10. 3390/cancers 10080253

Chung, M.-H., Wang, Y.-W., Chang, Y.-L., Huang, S.-M., and Lin, W.-S. (2017). Risk of cancer in patients with heart failure who use digoxin: a 10-year followup study and cell-based verification. Oncotarget 8, 44203-44216. doi:10.18632/ oncotarget. 17410

Cnossen, M., Van Essen, T. A., Ceyisakar, I. E., Polinder, S., Andriessen, T., Van Der Naalt, J., et al. (2018). Adjusting for confounding by indication in observational studies: a case study in traumatic brain injury. Clin. Epidemiol. 10, 841-852. doi:10.2147/clep.s154500

Couraud, S., Azoulay, L., Dell'aniello, S., and Suissa, S. (2014a). Cardiac glycosides use and the risk of lung cancer: a nested case-control study. BMC Cancer 14, 573. doi:10.1186/1471-2407-14-573

Couraud, S., Dell'Aniello, S., Bouganim, N., and Azoulay, L. (2014b). Cardiac glycosides and the risk of breast cancer in women with chronic heart failure and supraventricular arrhythmia. Breast Cancer Res. Treat. 146, 619-626. doi:10. 1007/s10549-014-3058-8

De Giorgi, V., Grazzini, M., Benemei, S., Marchionni, N., Botteri, E., Pennacchioli, E., et al. (2018). Propranolol for off-label treatment of patients with melanoma: results from a cohort study. JAMA Oncol. 4, e172908. doi:10.1001/jamaoncol. 2017.2908

Drew, D. A., Cao, Y., and Chan, A. T. (2016). Aspirin and colorectal cancer: the promise of precision chemoprevention. Nat. Rev. Cancer 16, 173-186. doi:10. 1038/nrc.2016.4

Eichhorn, E. J., and Gheorghiade, M. (2002). Digoxin. Prog. Cardiovasc. Dis. 44, 251-266. doi:10.1053/pcad.2002.31591

Flahavan, E. M., Sharp, L., Bennett, K., and Barron, T. I. (2014). A cohort study of digoxin exposure and mortality in men with prostate cancer. BJU Int. 113, 236-245. doi:10.1111/bju.12287

Forbes, C. A., Deshpande, S., Sorio-Vilela, F., Kutikova, L., Duffy, S., GouniBerthold, I., et al. (2018). A systematic literature review comparing methods for the measurement of patient persistence and adherence. Curr. Med. Res. Opin. 34, 1613-1625. doi:10.1080/03007995.2018.1477747

Goldberger, Z. D., and Alexander, G. C. (2014). Digitalis use in contemporary clinical practice. JAMA Intern. Med. 174, 151-154. doi:10.1001/jamainternmed. 2013.10432

Lin, G. So. Y., and Johnston, G. (2012). Analyzing survival data with competing risks using SAS ${ }^{\circledR}$ SoftwareSAS global forum 2012. Cary, NC: SAS Institute Inc.

Haaland, G. S., Falk, R. S., Straume, O., and Lorens, J. B. (2017). Association of warfarin use with lower overall cancer incidence among patients older than 50 years. JAMA Intern. Med. 177, 1774-1780. doi:10.1001/jamainternmed. 2017.5512

Häggström, C., Stattin, P., Stocks, T., Garmo, H., Holmberg, L., and Van Hemelrijck, M. (2016). Interpretation of conventional survival analysis and competing-risk analysis: an example of hypertension and prostate cancer. BJU Int. 118, 850-852. doi:10.1111/bju.13494

Haldar, R., Shaashua, L., Lavon, H., Lyons, Y. A., Zmora, O., Sharon, E., et al. (2018). Perioperative inhibition of beta-adrenergic and COX2 signaling in a clinical trial in breast cancer patients improves tumor Ki-67 expression, serum cytokine levels, and PBMCs transcriptome. Brain Behav. Immun. 73, 294-309. doi:10.1016/j.bbi.2018.05.014

Hsieh, K.-P., Chen, L.-C., Cheung, K.-L., and Yang, Y.-H. (2015). A competing risk analysis of hormone therapy interruption in Asian women with breast cancer. Pharmacoepidemiol. Drug Saf. 24, 301-309. doi:10.1002/pds.3733

Jansen, L., Hoffmeister, M., Arndt, V., Chang-Claude, J., and Brenner, H. (2014). Stage-specific associations between beta blocker use and prognosis after colorectal cancer. Cancer 120, 1178-1186. doi:10.1002/cncr.28546
Juang, H.-H., Lin, Y.-F., Chang, P.-L., and Tsui, K.-H. (2010). Cardiac glycosides decrease prostate specific antigen expression by down-regulation of prostate derived Ets factor. J. Urol. 184, 2158-2164. doi:10.1016/j.juro.2010.06.093

Kaapu, K. J., Ahti, J., Tammela, T. L. J., Auvinen, A., and Murtola, T. J. (2015). Sotalol, but not digoxin is associated with decreased prostate cancer risk: a population-based case-control study. Int. J. Cancer 137, 1187-1195. doi:10. $1002 /$ ijc. 29470

Karasneh, R. A., Murray, L. J., Hughes, C. M., and Cardwell, C. R. (2015). Digoxin use after diagnosis of colorectal cancer and survival: a population-based cohort study. Cancer Epidemiol. Biomarkers Prev. 24, 1804-1807. doi:10.1158/10559965.epi-15-0694

Kirchhof, P., Benussi, S., Kotecha, D., Ahlsson, A., Atar, D., Casadei, B., et al. (2016). 2016 ESC Guidelines for the management of atrial fibrillation developed in collaboration with EACTS. Eur. Heart J. 37, 2893-2962. doi:10.1093/ eurheartj/ehw210

Kohl, M., Plischke, M., Leffondré, K., and Heinze, G. (2015). PSHREG: a SAS macro for proportional and nonproportional subdistribution hazards regression. Com. Meth. Progr. Biomed. 118, 218-233. doi:10.1016/j.cmpb. 2014.11.009

Kulkarni, Y. M., Kaushik, V., Azad, N., Wright, C., Rojanasakul, Y., O'doherty, G., et al. (2016). Autophagy-Induced apoptosis in lung cancer cells by a novel digitoxin analog. J. Cel. Physiol. 231, 817-828. doi:10.1002/jcp.25129

Lam, W. Y., and Fresco, P. (2015). Medication adherence measures: an overview. Biomed. Res. Int. 2015, 217047. doi:10.1155/2015/217047

Lau, B., Cole, S. R., and Gange, S. J. (2009). Competing risk regression models for epidemiologic data. Am. J. Epidemiol. 170, 244-256. doi:10.1093/aje/kwp107

Lim, Y. P., Lin, C. L., Lin, Y. N., Ma, W. C., Chen, W. C., Hung, D. Z., et al. (2015). Antiarrhythmic agents and the risk of malignant neoplasm of liver and intrahepatic bile ducts. PLoS One 10, e0116960. doi:10.1371/journal.pone. 0116960

Lin, Y. T., Wu, P. H., Chen, C. S., Yang, Y. H., and Yang, Y. H. (2016). Association between acetylcholinesterase inhibitors and risk of stroke in patients with dementia. Sci. Rep. 6, 29266. doi:10.1038/srep29266

Menger, L., Vacchelli, E., Adjemian, S., Martins, I., Ma, Y., Shen, S., et al. (2012). Cardiac glycosides exert anticancer effects by inducing immunogenic cell death. Sci. Translational Med. 4, 143ra99. doi:10.1126/scitranslmed.3003807

Nilsson, M. B., Sun, H., Diao, L., Tong, P., Liu, D., Li, L., et al. (2017). Stress hormones promote EGFR inhibitor resistance in NSCLC: implications for combinations with beta-blockers. Sci. Transl Med. 9, eaao4307. doi:10.1126/ scitranslmed.aao4307

Normand, S.-L. T., Landrum, M. B., Guadagnoli, E., Ayanian, J. Z., Ryan, T. J., Cleary, P. D., et al. (2001). Validating recommendations for coronary angiography following acute myocardial infarction in the elderly. J. Clin. Epidemiol. 54, 387-398. doi:10.1016/s0895-4356(00)00321-8

Osman, M. H., Farrag, E., Selim, M., Osman, M. S., Hasanine, A., and Selim, A. (2017). Cardiac glycosides use and the risk and mortality of cancer; systematic review and meta-analysis of observational studies. PLoS One 12, e0178611. doi:10.1371/journal.pone.0178611

Ouyang, X., Han, S.-N., Zhang, J.-Y., Dioletis, E., Nemeth, B. T., Pacher, P., et al. (2018). Digoxin suppresses pyruvate kinase M2-promoted HIF-1a transactivation in steatohepatitis. Cel Metab. 27, 339-350. doi:10.1016/j. cmet.2018.01.007

Platz, E. A., Yegnasubramanian, S., Liu, J. O., Chong, C. R., Shim, J. S., Kenfield, S. A., et al. (2011). A novel two-stage, transdisciplinary study identifies digoxin as a possible drug for prostate cancer treatment. Cancer Discov. 1, 68-77. doi:10. 1158/2159-8274.cd-10-0020

Ponikowski, P., Voors, A. A., Anker, S. D., Bueno, H., Cleland, J. G. F., Coats, A. J. S., et al. (2016). 2016 ESC Guidelines for the diagnosis and treatment of acute and chronic heart failure. Eur. Heart J. 37, 2129-2200. doi:10.1093/eurheartj/ ehw128

Prassas, I., and Diamandis, E. P. (2008). Novel therapeutic applications of cardiac glycosides. Nat. Rev. Drug Discov. 7, 926-935. doi:10.1038/nrd2682

Raebel, M. A., Schmittdiel, J., Karter, A. J., Konieczny, J. L., and Steiner, J. F. (2013). Standardizing terminology and definitions of medication adherence and persistence in research employing electronic databases. Med. Care 51, S11-S21. doi:10.1097/mlr.0b013e31829b1d2a

Sethi, N. J., Nielsen, E. E., Safi, S., Feinberg, J., Gluud, C., and Jakobsen, J. C. (2018). Digoxin for atrial fibrillation and atrial flutter: a systematic review with meta- 
analysis and trial sequential analysis of randomised clinical trials. PLoS One 13, e0193924. doi:10.1371/journal.pone.0193924

Su, V. Y.-F., Hu, Y.-W., Chou, K.-T., Ou, S.-M., Lee, Y.-C., Lin, E. Y.-H., et al. (2013). Amiodarone and the risk of cancer. Cancer 119, 1699-1705. doi:10. 1002/cncr.27881

Trenti, A., Zulato, E., Pasqualini, L., Indraccolo, S., Bolego, C., and Trevisi, L. (2017). Therapeutic concentrations of digitoxin inhibit endothelial focal adhesion kinase and angiogenesis induced by different growth factors. $\mathrm{Br}$. J. Pharmacol. 174, 3094-3106. doi:10.1111/bph.13944

Tsai, M. J., Wu, P. H., Sheu, C. C., Hsu, Y. L., Chang, W. A., Hung, J. Y., et al. (2016). Cysteinyl leukotriene receptor antagonists decrease cancer risk in asthma patients. Sci. Rep. 6, 23979. doi:10.1038/srep25880

Uretsky, B. F., Young, J. B., Shahidi, F. E., Yellen, L. G., Harrison, M. C., and Jolly, M. K. (1993). Randomized study assessing the effect of digoxin withdrawal in patients with mild to moderate chronic congestive heart failure: results of the PROVED trial. J. Am. Coll. Cardiol. 22, 955-962. doi:10.1016/0735-1097(93) 90403-n

Wang, T., Xu, P., Wang, F., Zhou, D., Wang, R., Meng, L., et al. (2017). Effects of digoxin on cell cycle, apoptosis and NF- $\mathrm{BB}$ pathway in Burkitt's lymphoma cells and animal model. Leuk. Lymphoma 58, 1673-1685. doi:10.1080/10428194. 2016.1256480

Watkins, J. L., Thaker, P. H., Nick, A. M., Ramondetta, L. M., Kumar, S., Urbauer, D. L., et al. (2015). Clinical impact of selective and nonselective beta-blockers on survival in patients with ovarian cancer. Cancer 121, 3444-3451. doi:10.1002/ cncr.29392

Wu, C. S., Lai, M. S., Gau, S. S., Wang, S. C., and Tsai, H. J. (2014). Concordance between patient self-reports and claims data on clinical diagnoses, medication use, and health system utilization in Taiwan. PLoS One 9, e112257. doi:10.1371/ journal.pone.0112257

Xie, S.-H., Jernberg, T., Mattsson, F., and Lagergren, J. (2017). Digitalis use and risk of gastrointestinal cancers: a nationwide population-based cohort study. Oncotarget 8, 34727-34735. doi:10.18632/oncotarget.16151

Zhao, Y. T., Li, P. Y., Zhang, J. Q., Wang, L., and Yi, Z. (2016). Angiotensin II receptor blockers and cancer risk: a meta-analysis of randomized controlled trials. Medicine (Baltimore) 95, e3600. doi:10.1097/md.0000000000003600

Conflict of Interest: The authors declare that the research was conducted in the absence of any commercial or financial relationships that could be construed as a potential conflict of interest.

Copyright (c) 2021 Tai, Yang, Tseng, Chang and Wang. This is an open-access article distributed under the terms of the Creative Commons Attribution License (CC BY). The use, distribution or reproduction in other forums is permitted, provided the original author(s) and the copyright owner(s) are credited and that the original publication in this journal is cited, in accordance with accepted academic practice. No use, distribution or reproduction is permitted which does not comply with these terms. 